\title{
A educação inclusiva em escolas multisseriadas do campo na amazônia paraense
}

\author{
Inclusive education in multi-seasoned schools of the field \\ in the paraense amazon
}

\author{
Ronielson Santos das Mercês ${ }^{1}$ \\ Ivanilde Apoluceno de Oliveira ${ }^{2}$
}

\section{Resumo}

Neste artigo apresenta-se o recorte de uma pesquisa de campo concluída em 2017. A questão problema é: como se efetiva a interface da educação especial e a do campo, em comunidades ribeirinhas de Belém do Pará, em escolas multisseriadas? O objetivo é analisar a interface entre a educação especial e a educação do campo, identificando as assimetrias, as condições e o trabalho docente com aluna com deficiência física em turma multisseriada de uma escola da Ilha do Combú-Pará. A metodologia é uma pesquisa qualitativa fundamentada na concepção dialética da educação. Os procedimentos metodológicos da pesquisa foram o levantamento bibliográfico, a observação in loco, com registro no diário de campo e a entrevista semiestruturada. A sistematização e a análise dos dados foram tratadas por meio de categorizações e considerados os aspectos éticos da pesquisa. Os sujeitos da pesquisa foram o professor da sala regular e o coordenador pedagógico da escola pesquisada. Entre os resultados destaca-se que a educação especial ofertada na escola ribeirinha funciona em minimas condições, bem como os professores não possuem apoio pedagógico nem formação que os auxiliem na prática educativa com o público da educação especial.

Palavras-chave: Educação Especial. Educação do Campo. Escola multisseriada

\section{Abstract}

In this article is shown a piece of a search from a rural area school done in 2017. The main question is: How does it works the interface of special education and the rural area education, in Riverside communities of Belém do Pará, in many grades schools? The goal is to analyze the interface between the special

\footnotetext{
${ }^{1}$ Mestrando do Programa de Pós-Graduação em Educação da Universidade do Estado do Pará. Membro da Rede de Educação Inclusiva na Amazônia e do Núcleo de Educação Popular Paulo Freire da Universidade do Estado do Pará - UEPA. E-mail: ronicfi2012@gmail.com

2 Doutora em Educação. Pesquisadora e docente do Programa de Pós-Graduação em Educação da Universidade do Estado do Pará. Coordena a Rede de Educação Inclusiva na Amazônia e o Núcleo de Educação Popular Paulo Freire da Universidade do Estado do Pará UEPA. E-mail: nildeapoluceno@uol.com.br.
} 
education and education of the rural area, identifying as asymmetries, as conditions and the teaching work with student with disabilities in many schools grades of the Combú-Parás island. The methodology is a qualitative research based on the dialectic conception of education. The methodological procedures of the research were the bibliographic survey, the observation on campus, with record in the rural journal and the Interstructured interview. The systematization and analysis of the data was dealt with through categorizations and considered the ethical aspects of the research. The subjects of the survey were the teacher of the regular room and the pedagogical coordinator of the school researched. Among the results is that a special education offered at the Riverside School operates in minimum conditions, as well as teachers do not have pedagogical support or training that assist them in educational practice with the public of special education.

Key words: Special education. Rural area education. Many grades School.

\section{Introdução}

A Educação Especial, por ser um direito recente para os sujeitos com deficiência do campo, intenta questões investigativas pouco pesquisadas no âmbito da academia brasileira, no que tange ao acesso à educação em escolas do campo na região amazônica, entre as quais, as condições de escolarização do alunado com deficiência e as condições físicas, pedagógicas e estruturais das escolas públicas. Revela-se como um tema desafiador, uma vez que a Educação Especial e a sua interface com a Educação do Campo são consideradas um direito social (CAIADO; MELLETI, 2011, p. 02).

As questões socioeducacionais que os alunos com deficiência enfrentam nos espaços educativos, repercutem na vida dos atores das escolas do campo, que anseiam a valorização e o reconhecimento das diferenças culturais, educacionais e sociais das comunidades escolares do campo da região amazônica.

Na Política Nacional de Educação Especial, na Perspectiva Inclusiva, o processo educacional perpassa pela educação indigena, do campo e quilombola, devendo ser assegurados os recursos, os serviços e o atendimento educacional especializado por meio de projetos pedagógicos construídos com base nas diferenças socioculturais desses grupos (BRASIL, 2008). 
Desta forma, o direito à educação especial no campo é garantido na legislação brasileira, a questão que se levanta é: como se efetiva esta interface da educação especial e a do campo, em comunidades ribeirinhas de Belém do Pará, em escolas multisseriadas?

As escolas multisseriadas fazem parte da realidade da educação do campo na Amazônia. Hage (2014) destaca que conforme dados do Censo Escolar de 2011, o estado do Pará é o que possui o maior número de turmas multisseriadas da Região Norte, o equivalente a 11.709 turmas (12,27\%). Acrescenta que essas escolas apresentam um quadro precário de infraestrutura e de condições de trabalho pedagógico, que interfere no processo de escolarização de seu alunado. Situação esta, que instiga a investigação nestas escolas, de como se efetiva o atendimento do alunado da educação especial, considerando, também, que a educação escolar em comunidades ribeirinhas envolve uma rede de significados, saberes e práticas sociais que tecem o movimento da construção da identidade dos estudantes amazônidas com ou sem deficiência da Amazônia.

Assim, neste artigo apresenta-se o recorte de uma pesquisa concluída em 2017, e realizada em uma escola ribeirinha do Combú, vinculada à Prefeitura de Belém, constituída por turmas multisseriadas e pelo atendimento educacional de educanda com deficiência física.

O objetivo é analisar a interface da educação especial com a educação do campo, identificando as assimetrias, as condições e o trabalho docente com aluna que apresenta deficiência física em turma multisseriada de uma escola situada na Ilha de Combú, no Distrito de Outeiro, no Estado do Pará.

Apresenta-se, inicialmente, a metodologia, em seguida, a interface entre a educação especial e a educação do campo identificando as assimetrias e o trabalho docente em turma multisseriada de uma escola da Ilha de Combú.

\section{Metodologia}

A pesquisa realizada em uma escola situada na Ilha do Combú, vinculada à Prefeitura de Belém, que faz parte do Distrito Administrativo do Outeiro 
(DAOUT) e compreende uma área de aproximadamente 15 quilômetros quadrados (RIBEIRO, 2010; MATTA, 2006).

A metodologia deste trabalho é uma pesquisa de campo de abordagem qualitativa, que de acordo com Chizotti (2003, p.02) "implica uma partilha densa com pessoas, fatos e locais que constituem objetos de pesquisas, para extrair desse convívio os significados visíveis e latentes que somente são perceptíveis a uma atenção sensivel”.

A pesquisa está fundamentada na concepção dialética da educação que considera "os elementos internos, as contradições no interior do indivíduo e da própria instituição educacional” (GADOTTI, 2006, p.159). No campo da educação especial as principais referências são Oliveira (2011); Caiado e Melletti (2011); Fernandes (2015), entre outros.

Os procedimentos metodológicos da pesquisa foram o levantamento e a revisão bibliográfica, a observação in loco, com registro no diário de campo e a entrevista semiestruturada, com registros fotográficos. A sistematização e a análise dos dados foram tratadas por meio de categorizações e considerados os aspectos éticos da pesquisa.

Os sujeitos da pesquisa foram o professor da sala regular e o coordenador pedagógico da escola pesquisada. A nominação dos profissionais da educação foi efetivada por meio de nomes fictícios para preservar à identidade dos sujeitos participantes.

\section{A interface entre a Educação Especial e a Educação do campo em uma escola multisseriada da Ilha do Combú- Pará}

Na realidade da educação especial na Ilha do Combú constata-se uma assimetria entre a oferta dessa modalidade de ensino para a área urbana e a do campo, em relação às condições de acesso, permanência e qualidade de ensino para os alunos com deficiência que estudam em escolas de comunidades escolares ribeirinhas.

O professor Jair relata sobre as condições de trabalho na educação especial em turmas multisseriadas, que são diferenciadas da capital paraense, 
apontando a multiciclagem/multisseriada como um fator a mais de dificuldade.

Observo que ainda tem uma grande diferença, na forma de se tratar, de conceber a Educação Especial, principalmente nas ilhas de Belém. Em Belém, você ainda encontra um recurso, um subsídio e acompanhamento, mas nas ilhas a questão ainda está muito lenta. Isso se dá desde a sala de aula, quanto tu adentras aos espaços da escola, na questão da acessibilidade e planejar. Para eu fazer um planejamento, eu tenho que pensar principalmente no turno da tarde, onde eu tenho a aluna, tenho que pensar o planejamento para duas turmas, sendo a turma multiciclo, no caso é multissérie $4^{\circ}$ e $5^{\circ}$ ano e ainda tem esse diferencial (PROF. JAIR)

Em seu discurso o professor Jair destaca que a invisibilidade da educação especial no campo é causada pelo fato dos setores responsáveis por esta educação estarem distantes da realidade ribeirinha e também por não terem acesso às pesquisas, aos dados e os registros da demanda de alunos com deficiência que estão matriculados nas Unidades Pedagógicas na região insular das ilhas de Belém, colaborando para manter as lacunas no atendimento educacional especializado dos alunos ribeirinhos com deficiência.

O aluno faz parte da rede e quando a gente vai buscar esse suporte pra fazer conhecer essas crianças, por que hoje em dia nós não temos esse dado completo de quantas crianças tem deficiência, por quê? Porque ninguém veio pesquisar, veio conversar, saber realmente (PROF. JAIR).

O professor evidencia que a ausência de informações por parte das equipes técnicas contribui para a marginalização dos alunos com deficiência, que se tornam sujeitos esquecidos pelos sistemas de ensino, ocasionando sérios comprometimentos na educação escolar no campo, por falta de prestação dos suportes necessários a esse alunado.

Caiado e Melletti (2011, p. 11) ressaltam que o direito à escola compreende a matrícula, a permanência, a apropriação do conhecimento para participação social e o respeito às especificidades do sujeito, desencadeadas não só pela condição de deficiência, mas também pelas peculiaridades 
culturais e sociais da vida no campo. Dessa maneira, na educação escolar no campo, os alunos com deficiência, seguem o mesmo curso de oferta do ensino básico, mas precisa ser considerado o seu perfil educacional e o seu tempo de aprendizagem, para ser garantido um ensino de qualidade e uma aprendizagem satisfatória.

O Professor Jair relata uma situação que contribui para o não atendimento inclusivo do aluno com deficiência: o não registro como aluno deficiente no sistema de matricula da Rede Municipal de Ensino.

Então, se a gente for observar pela matricula, pelo sistema SIGA nós não vamos encontrar, e isso vai acarretar lá na frente, quando esse aluno vai fazer as avaliações, tanto a nível município, como a nivel federal, que se esse aluno não consta lá no sistema como deficiente. Esse aluno não vai receber uma prova adaptada para aquela deficiência, não vai ter um atendimento especifico, ai acaba esbarrando na mesma tecla, de que é preciso olhar, é preciso ver de que forma está trabalhando melhor esse lado da Educação Especial, por que nós sabemos quem é essa demanda nas ilhas. (PROF. JAIR).

O professor destaca que a demanda de alunos com deficiência ribeirinhos registrados no sistema de matricula da Secretária Municipal de Ensino, não corresponde aos números de alunos com deficiência matriculados nos estabelecimentos de ensino, o que prejudica o acesso a serviços especializados que são garantidos por Lei, bem como à captação de recursos federais para implementação de programas, mobiliários e materiais pedagógicos adaptados para oferta da modalidade de ensino em comunidades ribeirinhas.

Mendes (2010, p. 77) destaca que "a não identificação neutraliza a diferença e, além disso, impede que serviços de suportes possam ser oferecidos, ficando esses alunos sujeitos a condições iguais, porém não equiparáveis".

\section{A educação especial no campo: precariedade nas condições de trabalho}


Identificou-se existir um descaso da educação especial nas escolas do campo, que funcionam em minimas condições estruturais, dificultando o acesso ao saber escolar por parte dos alunos com deficiência que vivem no campo. Além disso, nem todas as escolas do campo possuem salas de recursos multifuncionais, como é o caso da escola da Ilha de Combú.

Segundo o Coordenador Pedagógico Paulo: "quando nós tínhamos a assessora da Educação Especial aqui na Unidade, os atendimentos aconteciam na sala de aula ou na biblioteca, porque nós não temos sala de recurso multifuncional".

A escola Combú tinha assessora da educação especial que atuava nas Unidades Pedagógicas nas Ilhas de Belém, desenvolvendo o trabalho educacional itinerante com os alunos da Educação da Especial, uma vez por semana. A professora ia às escolas das Ilhas desenvolver o atendimento educacional especializado com esses alunos, todos os dias da semana, exceto na sexta-feira, dia marcado para fazer o planejamento pedagógico na Secretaria Municipal de Educação de Belém.

Nessa escola o atendimento com a aluna com deficiência física acontecia todas as terças-feiras, buscando desenvolver estratégias pedagógicas diferenciadas para as necessidades que aluna apresentava em sala de aula.

Segundo o professor Jair, quando a assessora realizava o atendimento especializado com a educanda o processo educativo tornava-se satisfatório e que depois de sua saída o trabalho pedagógico ficou mais difícil para ele.

Por exemplo, nós planejávamos a atividade, ela propunha algumas atividades já adaptadas para aluna, ficava melhor de se trabalhar. Ela fazia o acompanhamento da aluna, mas se eu não tenho uma base para este acompanhamento. Mas infelizmente ela saiu da Educação Especial, [...] aí é mais dificultoso para mim trabalhar em sala de aula (PROF. JAIR).

O professor reforça que somente o atendimento educacional especializado realizado pela professora especializada, uma vez por semana, de caráter itinerante, não é suficiente para atender às necessidades dos alunos com deficiência que estudam nas escolas do campo, dificultando o desenvolvimento escolar desses educandos no contexto da sala multiciclada 
das Ilhas. O docente informou, também, que sente dificuldade em trabalhar com a aluna com deficiência no contexto da sala de aula multiciclada/multisseriada, tanto em relação aos conteúdos curriculares quanto às atividades pedagógicas direcionadas para incluir a aluna no contexto escolar.

Percebe-se na fala do coordenador que o Atendimento Educacional Especializado disponibilizado para os alunos com deficiência na Unidade Pedagógica do Combú, não segue as diretrizes deste atendimento da Política de Educação Especial na Perspectiva da Educação Inclusiva, que estabelece:

o atendimento educacional especializado deve identificar, elaborar e organizar recursos pedagógicos e de acessibilidade que eliminem as barreiras para a plena participação dos estudantes, considerando suas necessidades específicas. As atividades desenvolvidas no atendimento educacional especializado diferenciam-se daquelas realizadas na sala de aula comum, não sendo substitutivas à escolarização (BRASIL, 2008, p. 16).

A ausência de salas de recursos multifuncionais interfere no Atendimento Educacional Especializado do aluno com deficiência, que deixa de ter acesso ao ensino complementar e diferenciado da prática pedagógica da sala da comum. Com isso, o atendimento especializado, quando acontece, é realizado em espaços físicos sem recursos e materiais pedagógicos que subsidiem o processo educativo dos alunos da educação especial.

Marcoccia (2009, p. 03) destaca as carências de recursos pedagógicos e ações afirmativas por parte do estado no acesso escolar dos alunos com deficiência nas escolas do campo:

educação Especial no Campo apresenta outros contextos socioculturais e econômicos que diferem do contexto urbanoindustrial. A questão é que apenas esses dispositivos legais não garantem o direito real dos estudantes do campo com NEE ao acesso e permanência nas escolas públicas. Na prática, muito pouco se tem visto do desenvolvimento dessas politicas da implementação dessas diretrizes e das ações para garantir esse direito.

Assim, constatamos a ausência de implementações de diretrizes e ações de políticas públicas na escola pesquisada do Combú, em razão, da falta de uma sala de recurso multifuncional, ausência de rampa de acessibilidade e de 
mobiliário adequado e carência de formação continuada para os professores na área de educação especial e dos anos iniciais, indicando que os preâmbulos legais se distanciam do contexto educacional ribeirinho.

As escolas do campo funcionam com as mínimas condições de oferta da educação escolar para os alunos com deficiência do campo, como bem assenta Fernandes (2015. p. 5) "na ausência de politicas públicas para a população do campo, seja em educação, saúde, transporte, moradia e trabalho, revela-se o impedimento de pessoas com deficiência viverem com dignidade e participarem da vida social".

Esses fatores interferem de forma negativa na inclusão escolar de alunos com deficiência em escolas do campo. Caiado et al (2016, p. 16) problematizam que:

para um aluno chegar à escola, nela permanecer e aprender precisam ser garantidas inúmeras e complexas condições. Principalmente quando é um aluno com deficiência em que as barreiras sociais de toda ordem impedem a convivência social e seu desenvolvimento. Com isso, conhecer a realidade é fundamental para a formulação e implementação de propostas que promovam a superação dos desafios.

As autoras ressaltam que os alunos da educação especial que estudam nas escolas do campo devem ter o seu direito social garantido, sendo desenvolvido um ensino com condições de qualidade e favorecendo a educação inclusiva nos projetos políticos pedagógicos das escolas do campo.

O projeto político pedagógico das escolas das Ilhas, entre as quais a de Combú, precisam ainda levar em conta as questões socioculturais, sociopedagógicas dos alunos com deficiência que vivem em comunidades ribeirinhas, construindo um projeto de educação que valorize os saberes e contribua para a construção da identidade cultural do aluno ribeirinho com deficiência.

\section{A interface entre a educação do campo e a educação especial no trabalho pedagógico em turmas multisseriadas na Ilha do Combú}


Os docentes que atuam na escola do Combú seguem a mesma lógica das classes seriadas para ministrarem os conteúdos curriculares, desenvolvendo as aulas a partir dos descritores curriculares da rede de ensino municipal direcionados para os alunos do campo.

\section{A lógica seriada: modelo urbanocêntrico}

Os docentes no horário da manhã desenvolvem as atividades, os trabalhos, as provas e os conteúdos em consonância com os descritores. No horário da tarde, o professor que atua com a turma multiciclada sente dificuldade em trabalhar os descritores com os alunos, pois são duas turmas em uma única sala, sendo o trabalho pedagógico desafiador para desenvolver com os alunos com/sem deficiência em turmas multicicladas.

O professor Jair explica sobre a educação multiciclo/multisseriada.

$\mathrm{Na}$ verdade, essa educação multiciclo, multisseriada, é uma realidade constante nas ilhas, é dificil hoje em dia você tentar como dizer minimizar o número de turmas, porque são turmas pequenas, tenho que ciclar as turmas, multiciclar tu não consegues. Então, eu tenho que multisseriar, ou seja, é duas turmas dentro um ciclo, mas se tu fores olhar quase todas as unidades tem, e aí é mais complicado o teu trabalho, porque quando é apenas um ciclo, uma única turma, só um ciclo é melhor para você planejar (PROF. JAIR).

A divisão em ciclos, por meio de turmas multisseriadas, caracteriza as turmas como multicicladas, o que segundo o professor Jair, dificulta o processo ensino-aprendizagem.

O professor da turma não divide os conteúdos das disciplinas entre as turmas do $4^{\circ}$ e $5^{\circ}$ ano, porque todos aprendem os mesmos conteúdos. Em algumas situações o professor realiza a divisão dos assuntos por temas geradores, geralmente, quando realiza excursões pedagógicas em que cada educando tem de pesquisar um tema, contemplando os conteúdos curriculares.

Os professores que lecionam na escola ribeirinha do Combu, nenhum teve contato com os alunos da educação especial, somente o professor Jair ao 
ingressar na Secretaria Municipal de Belém, designado para atuar nas ilhas de Belém, teve seu primeiro contato com alunos com deficiência. Ele relatou em sua entrevista:

Em 2009, por aí assim, na verdade foi a minha primeira experiência, com aluno da educação especial, nunca tive nenhuma experiência com aluno com deficiência comprovada. Aluna $M$ foi minha primeira aluna e a depois a aluna $F$ minha segunda aluna aqui no Combú que é cadeirante (PROF. JAIR).

Para o professor que já atuava no contexto educacional ribeirinho em outro município, o fato de ter aluno com deficiência estudando em escolas ribeirinhas de Belém, causou-lhe "estranheza", por acreditar que as dificuldades para educar esses alunos em áreas rurais são mais desafiadoras para o trabalho docente. Explica o professor Jair em relação ao uso dos descritores com a aluna com deficiência:

Os descritores são trabalhados em Língua Portuguesa e Matemática. Para ela eu tento sempre, como ela tem muita limitação na escrita, uma dificuldade muito grande, tem que ter mais atividades com os desenhos, porque ela pode observar, ela pode manusear. Para que ela possa estar manuseando, porque na escrita ela não tem mesmo, ela não consegue acompanhar sempre e ela não tem uma leitura, a leitura dela ainda está em processo lento. Quanto ao raciocínio lógico matemático ela não consegue resolver as atividades, mas para isso, eu tenho que trazer tudo pronto de casa para ela e ai ela já consegue fazer o exercício do raciocínio lógico matemático, ela tem dificuldade pra Língua Portuguesa, é o que observo muito (PROF. JAIR).

O professor busca realizar atividades que atendam as exigências dos descritores da SEMEC, para que a aluna participe das atividades escolares, todavia as atividades propostas não atendem às especificidades da educanda e não contemplavam aos objetivos educacionais estipulados para a escolarização da aluna. Por isso, utiliza a estratégia do desenho e também traz atividades prontas, para facilitar o processo de aprendizagem da educanda.

Observou-se em sala, na aula de matemática, que o assunto para ser trabalhado de acordo com os descritores era geometria. O docente levou para sala de aula figuras geométricas em uma folha de papel A4, para aluna 
reconhecer suas formas, espessuras e áreas. Posteriormente, montou com massa de modelar e palitos de dentes, figuras geométricas para aluna manusear em sala e visualizar suas formas.

Outro assunto trabalhado com a aluna, na aula de matemática, foi o uso das operações matemáticas de soma e subtração; centena, dezena e unidade, com a utilização do recurso pedagógico material dourado, com o objetivo de a aluna contabilizar os seus cálculos e expor para a turma.

O professor Jair procurou realizar estratégias pedagógicas para que a aluna realizasse e participasse das atividades educativas propostas para turma em sala de aula, trazendo de casa materiais e atividades que contemplasse os conteúdos curriculares a serem trabalhados com a aluna.

Fig. 01: A aula de matemática com material dourado

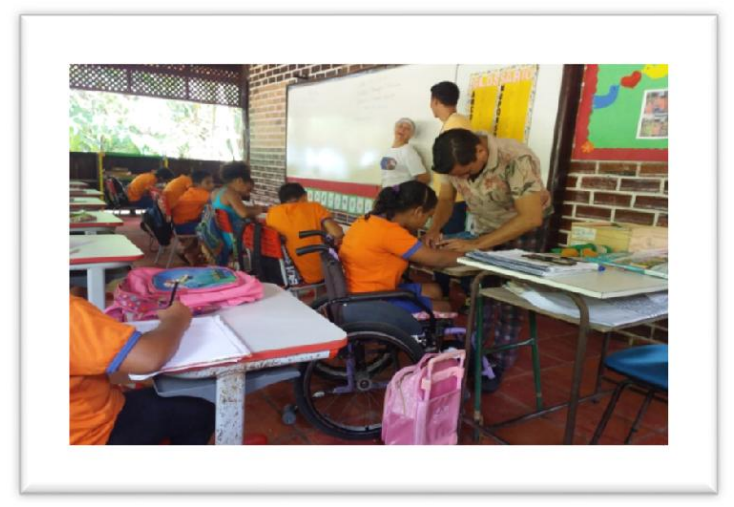

Fonte: Mercês (2017).

$\mathrm{Na}$ resolução de problemas e exercícios o professor sempre perguntava sobre as questões das atividades, para promover a socialização da aluna com os demais alunos em sala de aula.

Identifica-se, que o professor Jair compreende a necessidade de incluir a aluna no cerne do trabalho pedagógico em sala de aula multiciclada/multisseriada, mesmo sendo difícil em algumas situações, bem como que a utilização de recursos pedagógicos como o material dourado favoreceu uma melhor compreensão dos objetivos das atividades em sala de aula por parte da aluna com deficiência. Entretanto, o fato do professor levar atividades prontas elaboradas por ele, provoca um cerceamento da capacidade da educanda em criar, em elaborar suas próprias produções. 
O professor Jair também destaca que precisa fazer dois planejamentos um para a sala de aula regular e outro para a aluna com deficiência, o que dificulta o seu trabalho pedagógico.

o meu planejamento é feito semanal, na terça-feira é que eu vou para formação na minha Hora Pedagógica - HP. Geralmente, como eu sou dos dois ciclos, com o ciclo dois é praticamente o mês todo, porque eu me planejo tanto para o $3^{\circ}$ ano, quanto para o ciclo 2 que é o $4^{\circ}$ e $5^{\circ}$ ano, já é um desdobramento muito maior e, ainda tem que fazer um planejamento para $\mathrm{F}$. que é a aluna [com deficiência], um planejamento diferenciado (PROF. JAIR).

O professor, então, separa o planejamento pedagógico, um voltado para os discentes que estudam nas turmas multisseriadas e outro para a aluna com deficiência. Entretanto, a aluna com deficiência estuda regularmente com os demais colegas em sala, não havendo necessidade em diferenciar as atividades educativas. Este fato pode contribuir para o processo de segregação da aluna perante o coletivo da sala de aula.

Considera-se que o trabalho pedagógico pensado pelo professor visa promover a inclusão da aluna com deficiência em turma multisseriada, porém não viabiliza a participação da aluna em atividades criativas proporcionando à aluna ser sujeito de seu conhecimento.

Conforme Oliveira (2011, p. 115) “o fato de os educandos estarem juntos não significa estarem incluídos. A inclusão escolar pressupõe o respeito à diversidade cultural e as diferenças individuais dos educandos". De fato, na visão da autora a educação inclusiva deve estar para além de integrar o aluno, devendo promover o diálogo entre as diferenças no contexto da sala de aula para que possam estar se reconhecendo nas suas alteridades.

Carvalho (2004, p.110) reforça que "a proposta de inclusão é muito mais abrangente e significativa do que o simples fazer parte (de qualquer aluno), sem assegurar e garantir sua ativa participação em todas as atividades processo de ensino [...]". Dessa maneira, não é suficiente o educando com deficiência estar fisicamente em sala de aula, mas os sujeitos devem estabelecer diálogos, encontros e momentos de socialibilidade nas atividades pedagógicas proposta pelo professor. 
Fernandes (2015) salienta que o desafio da educação inclusiva é um conjunto de alunos com/sem deficiência em classes comuns, decorrendo-se das formas básicas de aprender o conhecimento, construindo a participação com igualdade de condições do mundo letrado, dos grupos sociais em que está inserido, de modo a se constituírem-se como individuo, como cidadãos, e assim poderem compartilhar do social, do modo de viver.

Observou-se, também, que a aluna com deficiência não participou das avaliações regionais e nacionais, pelo fato de não atender as exigências de ler e escrever. Com isso, não participou do processo avaliativo, sendo segregada no âmbito da turma e da escola.

Assim, o trabalho pedagógico no campo com alunos da educação especial não contempla e nem problematiza as questões educacionais desses alunos no processo educativo das escolas ribeirinhas. O olhar para o aluno inserido nesse contexto de aprendizagem, tem sido um discurso de dificuldades por parte do professor tanto no ato de planejar quanto na prática docente, configurando-se em uma tarefa dificil a inclusão no contexto das escolas multicicladas/multisseriadas.

\section{Dificuldades no processo ensino-aprendizagem}

Destaca-se, ainda, na fala do professor, a carência de materiais pedagógicos para o processo educativo dos alunos com deficiência em turmas multicicladas das escolas ribeirinhas, bem como a falta de uma formação que possibilite um outro olhar pedagógico ao docente.

Ainda tem uma outra questão quando se fala nesse aspecto da Educação Especial para atender, é o material didático, que não te dá também esse suporte. É uma outra questão fundamental, como é que eu planejo o material se eu não tenho esse olhar diferente, esse olhar cauteloso para trabalhar com esse aluno, se a gente for observar tivemos avanços? Tivemos poucos, mas ainda precisa muito ser feito nesse ramo, para atender esses alunos sabemos que as leis tratam, mas temos esses desdobramentos, que acabam interferindo no ensino/aprendizagem (PROF. JAIR). 
Para o professor Jair só é possivel oferecer uma educação escolar que atenda às necessidades desses alunos, de forma sensivel e atente para a realidade educacional em que estão situados. O docente afirmou: "eu acho que tudo começa pela tua formação, eu acho que quando tu sabes que vou trabalhar com esse aluno, que tem esse aluno em sala de aula, eu acho que uma das coisas fundamentais para um professor é a formação".

Apresenta, então, na sua fala, um aspecto fundamental para a inclusão educacional dos alunos da educação especial, a formação continuada de professores. O professor destaca ainda existir uma precariedade na formação proporcionada pela Rede municipal de ensino, a ausência de explicação de como realizar um trabalho pedagógico diferenciado e que leve em conta a realidade sociocultural do educando ribeirinho.

Eu vejo que é preciso que esses sistemas que te oferece essa formação, te mostrem como tu deves trabalhar com esse aluno em sala de aula, com esse trabalho diferenciado, por mais que eles te passem informação, contribua no processo, mas é preciso ter esse olhar com aluno em sala de aula, principalmente o aluno ribeirinho (PROF. JAIR).

Ponzo (2010, p. 131) destaca que a formação de professores para atuar com os alunos com deficiência nas escolas do campo constitui em uma educação que não é levada em consideração, bem como não respeita as condições de trabalhos dos educadores, seus horários, os alunos concretos que estão em sala de aula, os anseios da comunidade e as temáticas que necessitam estar incorporadas à formação continuada de professores da zona rural.

Desta forma, os Centros de formação não visualizam os alunos com deficiência nas escolas ribeirinhas, direcionando as questões formativas do professor somente para os alunos do centro urbano, invisibilizando esses alunos no contexto educacional das ilhas, não dando suporte técnico e pedagógico para prática educativa do professor do campo que atua com esses sujeitos em sala de aula multiciclada.

Fernandes (2015, p. 231) aponta que a formação de professores da SEMEC não está evidente a concepção de formação continuada dos docentes, 
haja vista que não propicia aos professores momentos reflexivos e construção da sua própria prática, a contrário, apresenta-se veementemente tecnicista em que ensinar a ensinar. Contribui para um ensino escolar desigual e técnico, deslocando-se das questões do campo no processo formativo, ressaltando o destaque de ter bons resultados em exames regionais e nacionais.

O professor Jair informou que a falta de avaliações adaptadas, de recursos pedagógicos, e serviços especializados, se deve pelo fato, do Centro de Referência Gabriel Lima Mendes (CRIE/SEMEC), nunca ter realizado a visita técnica à Unidade Pedagógica do Combú, para prestar serviços, apoios e promover momentos formativos para os docentes do espaço educativo. $O$ docente afirmou: "nós temos dentro da rede o CRIE que atende diretamente essas crianças, mas durante esse período de eu estar nas ilhas, eu nunca vi nem uma pessoa vir te dar esse suporte de pelo menos te encaminhar algumas questões, para ti trabalhar melhor esse atendimento em sala de aula".

O professor Jair chama atenção para a responsabilidade do CRIE/SEMEC, em atender a modalidade da educação especial nas escolas localizadas nas Ilhas de Belém.

Eu acho que é preciso você olhar a Educação Especial, dar esse suporte, igual como você dá para esses alunos "ditos normais", porque se a gente for observar as dificuldades vão sempre existir, mas se eu enquanto órgão competente se eu puder melhorar tenho que fazer isso acontecer e nas ilhas a situação ainda é muito triste. Falo isso como profissional do dia a dia, se a gente for olhar muitas vezes isso perpassa desde a formação do professor, para atuar com esse aluno, não adianta eu ter nivel superior, ser concursado, mas se eu não tenho uma formação pra lidar no dia-a-dia com esse aluno (PROF. JAIR).

O docente explica que sente dificuldade em trabalhar com a aluna da educação especial em turmas multicicladas/multisseriadas.

Eu sinto dificuldade para trabalhar com aluna, eu sinto muitas vezes eu me pergunto o que é que eu vou fazer hoje com a atividade dela, mas quando participo nas formações eu vejo que não tem uma pessoa para te dar esse suporte, para te 
encaminhar é mais dificil, porque muitas vezes acaba recaindo sobre a tua prática pedagógica em sala de aula, quando você não consegue fazer com que aquele aluno avance, porque o que eu observo, a aluna tem condições, mas tem que dar esse suporte para ela (PROF. JAIR).

Para ele, a falta de suporte pedagógico dificulta a educação inclusiva nas comunidades escolares ribeirinhas, repercutindo na prática pedagógica com os alunos com e sem deficiência.

Nas palavras do entrevistado, a educação especial precisa ser "trabalhada e enfrentada. Eu acho, acima de tudo, ela deve ser incorporada por quem está no dia a dia, principalmente pelos professores que atuam aqui, mas eu acho pelas pessoas que representam a secretaria em si" (PROF. JAIR).

A educação especial e inclusão educacional dos alunos com deficiência são aspectos distintos, mas estabelece finalidades comuns, o oferecimento de uma educação pública do campo que valorize o contexto cultural dos alunos do campo e a garanta o acesso aos direitos sociais assegurados nas legislações educacionais.

Assim, a educação especial nas ilhas apresenta muitos problemas que dificulta a garantia do direito social dos alunos com deficiência que estudam nas escolas do campo, em especial, a carência de recursos pedagógicos, materiais didáticos e mobiliários, bem como ausência de formação continuada, que promovam uma aprendizagem significativa aos educandos com deficiência.

De acordo com Oliveira (2011, p. 156) as escolas do campo não atendem a politica de educação inclusiva, no sentido de assegurar as condições necessárias para que o professor atenda o aluno com necessidades educacionais especiais.

Gonçalves et al (2015, p. 327) afirmam que:

apesar de a interface estar garantida na legislação nacional, pouco se estuda sobre a vida de pessoas com deficiência que vivem em famílias de trabalhadores, seja no campo ou na cidade. Falar de inclusão como um fenômeno desvinculado das reais condições da vida nos coloca a discutir sobre um fenômeno etéreo, a-histórico, que pouco ou nada contribui para a superação dos desafios trazidos pela vida. 
Marcoccia (2011) explica que a escola tão somente é a única via de garantia dos direitos dos alunos com deficiência no campo, por isso não se pode esperar que as legislações e/ou as escolas, sozinhas, construam estratégias mais justas para todos, é preciso à mobilização dos movimentos sociais, da família e da sociedade civil organizada para tomar parte nas lutas pela educação de todos. Destaca a participação da comunidade escolar na luta por melhorias de uma educação do campo para os alunos com e sem deficiência, visando o sucesso educacional das escolas públicas do campo.

Para isso, há necessidade de problematizar-se na educação inclusiva no âmbito da educação especial, o papel da escola, a estrutura física, os materiais didáticos, os recursos pedagógicos e as práticas educativas que oportuniza uma permanência com sucesso educacional para os alunos com deficiência no campo.

\section{Busca em superar as dificuldades por meio do diálogo com os saberes e o contexto ribeirinho}

Entretanto, apesar das dificuldades no processo de inclusão escolar no contexto ribeirinho, o professor se identifica com a educação ribeirinha e gosta do que faz.

Eu já trabalhava em Abaeté como professor concursado, quando passei no concurso de Belém, vim embora e decidi continuar na área da educação ribeirinha que algo que gosto muito né, não trocaria porque eu tenho, eu sinto e me identifico com a educação ribeirinha, sempre me identifiquei gosto do que faço nas ilhas (PROF. JAIR).

Essa cultura de pertencimento na fala do entrevistado com a vida no campo, com o tipo de educação que se efetiva nesses espaços educativos e com a identidade ribeirinha, tornam-se fatores fundamentais para $\mathrm{o}$ conhecimento de saberes populares que os alunos com e sem deficiência trazem consigo para o contexto da sala de aula, possibilitando uma educação que dialogue com a pluralidade cultural da vida ribeirinha.

A sala de aula multiciclada/multisseriada heterogênea, com alunos com diferentes idades, com saberes diferenciados e práticas sociais 
desenvolvidas no campo, possibilita uma gama de saberes fundamentais para construção identitária e para os diálogos na prática educativa do campo.

Freire (2011) destaca a importância de se educar com o aluno, vencendo as barreiras educacionais que o trabalho docente pode encontrar no cotidiano escolar, buscando um ato significativo para vida escolar desse aluno, oportunizando os seus saberes para que juntos possam estar no movimento dialético de ensinar e aprender no processo educativo. Isto significa que no ato educativo há necessidade da escuta do aluno e do estabelecimento do diálogo pedagógico

Articular temas geradores do contexto sociocultural dos alunos ribeirinhos para construção do conhecimento escolar é importante, para viabilizar aos alunos com deficiência pensarem e refletirem sobre o seu contexto cultural em articulação com os saberes escolares.

Freire (2011) considera que a escola tem o dever de respeitar os saberes com que os educandos, sobretudo o das classes populares, trazem para a sala de aula, saberes socialmente construídos. Com isso, reforça que se deve discutir com os educandos, em razão das relações sociais que os mesmos vivem na experiência social, estabelecendo correlação com o conhecimento do senso comum e com os conteúdos curriculares na prática educativa do professor.

O professor Jair ressalta que gosta de pesquisar e trabalhar com os saberes da vida cotidiana.

Eu gosto dessa parte de investigar, pesquisar nas áreas ribeirinhas. É algo que eu gosto muito, só que eu tenho afinidade pela área de gênero, mas gosto, também, dos saberes da vida cotidiana, quem sabe no mestrado eu pesquise sobre isso (PROF. JAIR).

Para ele, os saberes são fundamentais para as comunidades ribeirinhas, se constituírem em um mecanismo de legitimidade da identidade do povo do campo, passando por questões culturais e sociais dessas comunidades tradicionais.

Nesse contexto, os alunos com deficiência do campo que moram e estudam em escolas públicas, pertencente ao contexto rural, tem os seus 
saberes reconhecidos nas práticas educativas nas escolas do campo ribeirinhas.

Os encontros educativos na escola ribeirinha de Combú mostram que os conteúdos curriculares trabalhados com a aluna com deficiência visam estabelecer um diálogo com o conhecimento prévio da aluna, com as atividades educativas que o professor realiza em sala de aula.

$\mathrm{Na}$ aula de ciências, o professor trabalhou com os alunos da turma do $4^{\circ}$ e $5^{\circ}$ ano, sobre alimentação e a origem dos alimentos, pedindo-lhes que fizessem uma atividade de casa, para descobrir quais os alimentos que tinha em suas residências.

A proposta de atividade foi interessante para aluna com deficiência, porque eram alimentos que faziam parte do seu cotidiano ribeirinho, fazendo com que a educanda pesquisasse um pouco mais sobre o contexto local. $\mathrm{Na}$ aula seguinte, os alunos foram para uma excursão ecológica identificar as matérias primas de alguns alimentos que tem na ilha e nas proximidades. Nas palavras do professor Jair:

eu busco temas que são do cotidiano do aluno, as atividades são pensadas e vivenciadas na sua realidade do campo, procurando estabelecer relação com que aprendem na escola, com os seus saberes, de alguma forma, busco incluir todos nas minhas atividades.

Na visão de Freire (2011, p, 24) o professor deve discutir alguns saberes fundamentais em sua pratica educativa, entre os quais os saberes da experiência:

[...] devem ser conteúdos obrigatórios à organização programática da formação docente. Conteúdos cuja compreensão, tão clara e tão lúcida quanto possivel, deve ser elaborada na prática formadora. É preciso, sobretudo, e ai já vai um destes saberes indispensáveis, que o formando, desde o principio mesmo de sua experiência formadora, assumindo-se como sujeito também de produção do saber.

Desta forma, a prática educativa deve possibilitar a interconexão de conhecimento entre o educador e o educando com vistas a criar formas e sentidos na construção do conhecimento, constituindo-se em uma relação dialética de ensinar e aprender. 
Diante desse contexto o processo educativo da aluna com deficiência que estuda na escola do Combú, configura-se como um processo em que professor e aluna estão construindo momentos de aprendizados por meio do diálogo de saberes e experiências.

Mantoan (2017, p 61) define que o ensino de qualidade parte "de condições de trabalho pedagógico e de formação de redes de saberes e de relações, que se enredam por caminhos imprevisiveis para chegar ao conhecimento".

Freire (2011) reflete que o educador que pensa e reflete sobre sua práxis com os educandos, dever pensar também, que a prática educativa deve está imbricada ao contexto local negado do aluno, permitindo uma reflexão permanentemente do processo avaliativo e educativo que realizamos com os nossos educandos.

O processo de reflexão sobre a prática educativa com os alunos do campo foi evidenciado pelo professor Jair, em vários momentos da entrevista. Segundo ele, o processo inclusivo para os alunos com e sem deficiência é um caminho difícil nas ilhas de Belém, por isso, procura a melhor maneira, para incluir e proporcionar aos alunos um processo educativo de qualidade, por meio do acesso ao saber escolar com melhores condições pedagógicas.

O professor Jair reverbera que os alunos com e sem deficiência encontram as mesmas dificuldades de acesso e permanência na escola das comunidades ribeirinhas, porque cada sujeito apresenta especificidades e necessidades no processo educacional.

Se para o aluno "dito normal", as lacunas já são bem amplas, imagine para um aluno que é deficiente que tem certa deficiência. Acho que é preciso estudar mais sobre a questão, o que nós temos de estudos [...] nós estamos ainda bem atrasados nessas questões e nós sabemos que são alunos que já estão 10 , 11 anos bastante tempo, desde a Educação Infantil e a gente precisa ver e pesquisar mais essa questão (PROF. JAIR).

De acordo com o entrevistado, as pesquisas cientificas são fundamentais para as propostas de melhorias das políticas públicas educacionais para os alunos com e sem deficiência do campo, considerando 
as lacunas existentes que esses sujeitos do campo encaram no cenário educacional brasileiro.

Assim, a educação especial poderá ser efetivada se for considerado o contexto cultural, social e pedagógico dos alunos na educação do/no campo, devendo ser explicita essa consideração nos documentos oficiais e diretrizes que fomentam orientações para a modalidade da educação do campo.

Nozu (2013) pontua que as populações do campo em condição de deficiência e das pessoas que vivem no campo, a garantia do direito social à educação tem se configurado, no Brasil, até certa medida, como atuação tímida, descentrada e ambivalente de ambas as modalidades de educação: a especial e a do campo, reafirmando, os desafios que esses sujeitos encontram na garantia de direitos das escolas públicas do campo.

\section{Considerações finais}

Os resultados desta pesquisa apontam para a relevância de estudos sobre a interface entre a educação do campo com a educação especial, com destaque para a educação na Amazônia, considerando que são poucos os estudos científicos que problematizam a educação escolar do campo no cenário educacional amazônico.

Constatou-se, também, que a modalidade da educação especial, ofertada para os alunos da educação especial na escola ribeirinha da Ilha do Combú pesquisada, funciona nas mínimas condições para a escolarização dos alunos com deficiência, bem como os professores não possuem apoio pedagógico nem formação que os auxiliem na prática educativa com alunos com deficiência. A escola do Combú necessita de uma sala de recurso multifuncional, rampa de acessibilidade, materiais pedagógicos e formação continuada para os docentes que atuam com os alunos da educação especial no contexto da sala de aula multiciclada.

As escolas ribeirinhas ainda seguem, apesar de sua realidade de turmas multisseriadas, o modelo urbanocêntrico com a lógica da seriação, bem como não identificam nos projetos políticos pedagógicos os alunos com deficiência. 
Entretanto, os professores da escola pesquisada criavam estratégias para incluí-los na perspectiva da educação inclusiva.

A prática educativa do professor da turma multiciclada com a aluna com deficiência inserida nesse contexto educativo, desvela muitas dificuldades, mas há a preocupação por parte do professor com a inclusão escolar da aluna. Por isso, produz materiais para serem trabalhados pela aluna em sala, porém, em alguns momentos, acaba por cercear a autonomia da aluna, que poderia auxiliar o professor na produção de materiais. Outro fato observado é que a aluna em alguns momentos é tratada como se tivesse deficiência intelectual, quando é cadeirante, sendo sua limitação no processo de locomoção.

Destaca-se que formação continuada é um aspecto relevante para os professores que atuam nas Ilhas. O professor compreende a sua limitação no trabalho pedagógico com a aluna com deficiência e aponta a necessidade da formação.

Assim, mesmo com as dificuldades, o professor compreende a importância do contexto ribeirinho para o processo educativo, buscando relacionar os saberes dos educandos com os saberes escolares, bem como reflete sobre sua prática cotidiana e valoriza seus saberes experienciais. Procura desenvolver uma prática educativa dialógica em interação com o contexto social e cultural dos educandos com e sem deficiência.

\section{Referências}

ELÉM. Secretaria Municipal de Belém. Conselho municipal de educação. Plano Municipal de educação do Município de Belém. 2015. Disponível em: http: / www.agenciabelem.com.br/multimidiaSGN/anexo/08.04.2015/a113 756d8de 146b69662e091dda888f1.pdf. Acesso em: 10 de julho. 2017.

BRASIL. Politica Nacional de Educação Especial na Perspectiva

da Educação Inclusiva. Brasília: MEC, 2008. Disponível em http: / / portal.mec.gov.br/index.php?Option=com_docman\&view=download\& alias $=16690$-politica-nacional-deeducacao-especial-na-perspectiva-daeducacao-inclusiva05122014\&Itemid=30192. Acesso em: 08 abr. 2017. 
CAIADO, Kátia Regina Moreno. GONÇALVES, Thaisa Graziela Gomes Lulinha. SÁ, Michele Aparecida. Linha Critica Brasília, DF, v. 22, nº 48, p. 324, 345, mai./ ago, 2016.

CAIADO, Katia Regina Moreno; MELETTI, Silvia Marcia Ferreira. Educação especial na educação do campo: 20 anos de silêncio no GT 15. Revista Brasileira de Educação Especial, Marília, UNESP, v. 17, p. 93-104, maioago. 2011.

CARVALHO, Roseta Elder de. Educação Inclusiva: Com os pingos nos "si", Porto Alegre: Mediação, 2004.

CHIZZOTTI, A. Pesquisa Qualitativa em Ciências Humanas e Sociais. Revista Portuguesa de Educação, Portugal Braga, v. 16, n.1, p. 12-20, 2003.

FERNANDES, Ana Paula Cunha dos Santos. A escolarização da pessoa com deficiência nas comunidades ribeirinhas da Amazônia Paraense. 280 f. Tese (Doutorado), Universidade Federal de São Carlos, São Carlos, 2015.

FREIRE, Paulo. Extensão ou comunicação. 15 ed. São Paulo: Paz e Terra, 2011.

Paulo. Pedagogia da autonomia: Saberes necessários à prática educativa. Paz e Terra: São Paulo, 2011.

GADOTTI, Moacir. Concepção dialética da educação: um estudo introdutório. São Paulo: Cortez, 2006.

GONÇALVES, Taís Graziela Gomes Lulinha. Alunos com deficiência na educação de jovens e adultos em assentamentos paulistas: experiências do PRONERA. 199f. Tese (Doutorado), Universidade Federal de São Carlos, São Carlos, 2015.

HAGE, Salomão Mufarrej. Escolas rurais multisseriadas: desafios quanto à afirmação da escola pública do campo de qualidade. Livro 3. In: Didática e Prática de Ensino na relação com a Sociedade. Fortaleza-CE: EDUECE, 2014.

MANTOAN, Maria Teresa Eglér. Ensinando a turma toda: as diferenças na escola. In: _ $\quad$ O desafio das diferenças nas escolas. $5^{\circ}$ ed. Petropólis: Rio de Janeiro: Vozes, 2017. p. 59 -67.

MARCOCCIA, Patrícia Correia de Paula. A (in) visibilidade da educação especial e da inclusão nas escolas localizadas no campo. IX Congresso Nacional de Educação- Educere. III Encontro Sul Brasileiro de Psicopedagogia. Curitiba, PUC/PR. 2009. 
MATTA, R. A. de A. Espacialidade e sustentabilidade na ilha do Combu: um olhar sobre a interface urbano-insular como forma de contribuir para a conservação do espaço na construção da sustentabilidade local. 140f. Dissertação de Mestrado, Universidade Federal do Pará, Belém, 2006.

MENDES, Enicéia Gonçalves, MALHEIRO, C. A. L. Sala de recursos multifuncionais: é possivel um serviço "tamanho único" de atendimento educacional especializado? In: MIRANDA, T. G.; GALVÃO FILHO, T. A. (Org.). O professor e a educação inclusiva: formação, práticas e lugares. Salvador: EDUFBA, 2012. p. 349-365.

NOZU, Washington Cesar Shoiti. Politica e gestão do atendimento educacional especializado nas salas de recursos multifuncionais de Paranaiba/MS: uma análise das práticas discursivas e não discursivas. 241 f. Dissertação de Mestrado Universidade Federal da Grande Dourados, Dourados, 2013.

OLIVEIRA, Ivanilde Apoluceno de. SANTOS, Tânia Regina Lobato dos, Politica de Educação inclusiva e Formação de Professores no municipio de Ananindeua - Pará. Belém: CCSE/UEPA, 2007

; FRANÇA, Maria do Perpétuo Socorro; SANTOS, Tânia Regina Lobato dos (orgs.). Educação em Classes Multisseriadas na Amazônia: singularidade, diversidade e heterogeneidade. Vol. 1. Belém: Eduepa, $2011 .$.

PARÁ, Resolução do Conselho Estadual de Educação. 001, de 05 de Janeiro de 2010, Belém, PA, 05 de junho de 2017.

PONZO, Maria Glória. A formação de professores do campo na perspectiva da interface. In: Diversidade e inclusão na educação do campo: povos, territórios, movimentos sociais, saberes da terra, sustentabilidade. Vitória: UFES, Programa de Pós-Graduação em Educação, 2010.

RIBEIRO, J. de A. Área de proteção ambiental da Ilha do Combu, Belém/PA: desafios de implantação e de gestão de uma unidade de conservação. 140 f. Dissertação de Mestrado, Universidade Federal do Pará. Belém, 2010. 